$$
\text { フォーラム }
$$

\title{
測定值による重み付けを用いた非線形最小二乗法による 薬物動態解析の統計学的問題点
}

\author{
矢 船 明 史*
}

(受付： 2000 年 12 月 20 日)

\section{緒言}

各被験者ごとに十分な数の血中薬物濃度の測定 值が得られている臨床試験では, 各被験者ごとの 血中濃度のプロフィールに対して薬物動態学的モ デルを当てはめ, 各被験者ごとの薬物動態学的パ ラメータを推定するという解析が一般的に行われ ている.臨床第 1 相試験がこの代表的な例である.

モデルを当てはめる際には, 測定値のばらつき が測定時点ごとに異なることを考慮して，重み付 き非線形最小二乗法が一般的に用いられる ${ }^{1 \sim 3)}$. 重 み付けにはいくつの方法があるが, 実際の薬物動 態解析では，測定值自身を用いて重み付けを行う 方法がしばしば用いられる。この方法が用いられ る理由の 1 つとして, 測定值をそのまま重みとし て使えるという簡便さが挙げられる。しかし，こ の重み付けを用いた場合には，たとえ測定時点数 をいくら増やしたとしても, バイアスの入ったパ ラメータの推定值しか得られないという統計学的 問題が生じる．実際の薬物動態解析では，この問 題点についてほとんど知られていないまま用いら れているのが現状である。この問題点については すでに Sheiner and Beal' ${ }^{1)}$ が示唆しているが, 彼 らはその理論的な根拠については述べていない.

本論文の目的は, 薬物動態解析にしばしば用い られる測定値自身による重み付けを用いた非線形 最小二乗法の統計学的問題点について, その理論 的な根拠を示したうえで，シミュレーションによ
る検討を行うことにある。まず，次節では測定值 による重み付けの統計学的問題点について述べ る.さらに, 静脈内注射の1-コンパートメントモ デルを用いたシミュレーションによる検討結果を 提示し, 最後に若干の考察を加える.

\section{1. 測定値による重み付けの統計学的問題点}

ある被験者について, $t_{1}, \cdots, t_{m}$ の $m$ 時点で測定 された血中薬物濃度の測定值が $y_{1}, \cdots, y_{m}$ であった とする，本論文では，表記を簡潔にするために， 被験者を表す添え字は省略する。薬物動態学的モ デルを用いた解析を行う場合には, 測定值 $y_{j}$ に対 して，次のようなモデルを仮定する。

$$
y_{j}=f\left(t_{j}, \boldsymbol{\theta}\right)+\varepsilon_{j}, \quad j=1, \cdots, m
$$

この式で, $f(・)$ は薬物動態学的モデルにより 規定される非線形関数, $\boldsymbol{\theta}=\left(\theta_{1}, \cdots \theta_{p}\right)^{\mathrm{T}}$ は $(p \times 1)$ の薬物動態学的パラメータベクトル, $p$ はパラ メータの個数， $\varepsilon_{j}$ は誤差項をそれぞれ表す.

重み付き非線形最小二乗法では, 各測定時点に おける重みを $w_{j}$ として, 測定值 $y_{j}$ とモデルによる 予測值 $f\left(t_{j}, \boldsymbol{\theta}\right)$ との誤差の重み付き二乗和

$$
U(\boldsymbol{\theta}) \equiv \sum_{j=1}^{m} w_{j}\left\{y_{j}-f\left(t_{j}, \boldsymbol{\theta}\right)\right\}^{2}
$$

を最小化することにより, 各被験者のパラメータ ベクトル $\boldsymbol{\theta}$ を推定する。実際には, 式(2)の $U(\boldsymbol{\theta})$ を $\boldsymbol{\theta}$ について微分したうえで,

キーワード：一致性, $M$-推定量

* 北里大学大学院臨床統計部門 $\uparrow 108-8641$ 東京都港区白金 5-9-1 


$$
\frac{\partial U(\boldsymbol{\theta})}{\partial \boldsymbol{\theta}} \equiv \sum_{j=1}^{m} w_{j}\left\{y_{j}-f\left(t_{j}, \boldsymbol{\theta}\right)\right\} \frac{\partial f\left(t_{j}, \boldsymbol{\theta}\right)}{\partial \boldsymbol{\theta}}=0
$$

とした方程式の解として, パラメータベクトル の推定值 $\hat{\boldsymbol{\theta}}$ を得ることになる. $\partial f\left(t_{j}, \boldsymbol{\theta}\right) / \partial \boldsymbol{\theta}$ が $(p \times 1)$ のベクトルであることから, 方程式 (3)が $p$ 次元連立方程式となっていることに注意されたい.

式(3)の解である $\hat{\boldsymbol{\theta}}$ を真のパラメータ $\boldsymbol{\theta}$ の推 定值とするということは, 当然のことながら, 測

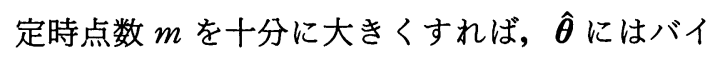
アスが入らないこと, すなわち $\hat{\boldsymbol{\theta}}$ が真のパラメー 夕 $\boldsymbol{\theta}$ の一致推定量 (consistent estimator) である ことを前提としている. $\hat{\boldsymbol{\theta}}$ が $\boldsymbol{\theta}$ の一致推定量で あるためには, 式(3)の $\partial U(\boldsymbol{\theta}) / \partial \boldsymbol{\theta}$ の $y_{j}$ に関す る期待値について,

$$
E\left[\frac{\partial U(\boldsymbol{\theta})}{\partial \boldsymbol{\theta}}\right]=0
$$

が成り立たなければならない. 条件(4)を満た

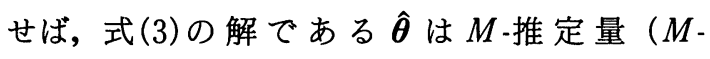

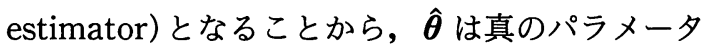
$\boldsymbol{\theta}$ の一致推定量となり ${ }^{4 \sim 6)}$ バイアスは入らない.し かし, 条件(4)を満たさない場合には $\hat{\boldsymbol{\theta}}$ は一致推 定量ではなくなり，バイアスが入ることになる.

ここで, 式(3)の $\partial U(\boldsymbol{\theta}) / \partial \boldsymbol{\theta}$ の期待值を考えて みる. 重み $w_{j}$ が測定値 $y_{j}$ の関数ではない場合に は, $y_{j}$ の期待値 $E\left[y_{j}\right]$ が $f\left(t_{j}, \boldsymbol{\theta}\right)$ に等しければ, すなわち, 各時点の測定值 $y_{j}$ の期待値 $E\left[y_{j}\right]$ を仮 定したモデル $f\left(t_{j}, \boldsymbol{\theta}\right)$ が正しく予測していれば,

$$
\begin{aligned}
E & {\left[\frac{\partial U(\boldsymbol{\theta})}{\partial \boldsymbol{\theta}}\right] } \\
& =E\left[\sum_{j=1}^{m} w_{j}\left\{y_{j}-f\left(t_{j}, \boldsymbol{\theta}\right)\right\} \frac{\partial f\left(t_{j}, \boldsymbol{\theta}\right)}{\partial \boldsymbol{\theta}}\right] \\
& =\sum_{j=1}^{m} w_{j} E\left[\left\{y_{j}-f\left(t_{j}, \boldsymbol{\theta}\right)\right\}\right] \frac{\partial f\left(t_{j}, \boldsymbol{\theta}\right)}{\partial \boldsymbol{\theta}} \\
& =\sum_{j=1}^{m} w_{j}\left\{E\left[y_{j}\right]-f\left(t_{j}, \boldsymbol{\theta}\right)\right\} \frac{\partial f\left(t_{j}, \boldsymbol{\theta}\right)}{\partial \boldsymbol{\theta}} \\
& =0
\end{aligned}
$$

となる.したがって, $E\left[y_{j}\right]=f\left(t_{j}, \boldsymbol{\theta}\right)$ が成り立っ ていれば, 式(4)の条件が成り立ち, 式(3)の解で

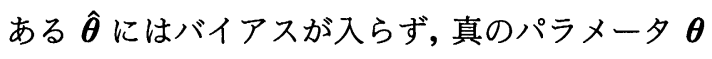

の一致推定量となる.この $y_{j}$ の一次モーメントに 関する条件 $E\left[y_{j}\right]=f\left(\mathrm{t}_{j}, \boldsymbol{\theta}\right)$ は, モーメントに関 する統計学的条件の中で最も緩いものである。こ の条件のもとで $\hat{\boldsymbol{\theta}}$ は一致推定量となる.

しかし，もしも重み $w_{j}$ が測定值 $y_{j}$ の関数である 場合には,たとえ条件 $E\left[y_{j}\right]=f\left(t_{j}, \boldsymbol{\theta}\right)$ が成り 立っていても式(4)の条件が成り立たない。した がって, $\hat{\boldsymbol{\theta}}$ は一致推定量ではなくなり, 測定時点 数 $m$ をいくら大きくしても $\hat{\boldsymbol{\theta}}$ にはバイアスが入 ることになる.この問題点について,以下に述べる.

測定值自身による重み付けとしては， $w_{j}=1 / y_{j}$ あるいは $w_{j}=1 / y_{j}{ }^{2}$ という重み付けが実際の薬物 動態解析にはよく用いられる. $w_{j}=1 / y_{j}$ という重 み付けを用いた場合を考えると，

$$
\begin{aligned}
E & {\left[\frac{\partial U(\boldsymbol{\theta})}{\partial \boldsymbol{\theta}}\right] } \\
& =E\left[\sum_{j=1}^{m} w_{j}\left\{y_{j}-f\left(t_{j}, \boldsymbol{\theta}\right)\right\} \frac{\partial f\left(t_{j}, \boldsymbol{\theta}\right)}{\partial \boldsymbol{\theta}}\right] \\
& =E\left[\sum_{j=1}^{m} \frac{1}{y_{j}}\left\{y_{j}-f\left(t_{j}, \boldsymbol{\theta}\right)\right\} \frac{\partial f\left(t_{j}, \boldsymbol{\theta}\right)}{\partial \boldsymbol{\theta}}\right] \\
& =\sum_{j=1}^{m} E\left[\left\{1-\frac{f\left(t_{j}, \boldsymbol{\theta}\right)}{y_{j}}\right\}\right] \frac{\partial f\left(t_{j,} \boldsymbol{\theta}\right)}{\partial \boldsymbol{\theta}} \\
& =\sum_{j=1}^{m}\left\{1-E\left[\frac{f\left(t_{j}, \boldsymbol{\theta}\right)}{y_{j}}\right]\right\} \frac{\partial f\left(t_{j}, \boldsymbol{\theta}\right)}{\partial \boldsymbol{\theta}}
\end{aligned}
$$

となることから,$E[\partial U(\boldsymbol{\theta}) / \partial \boldsymbol{\theta}]=0$ となるため には

$$
1-E\left[\frac{f\left(t_{j}, \boldsymbol{\theta}\right)}{y_{j}}\right]=0
$$

が成り立たなければならない， $y_{j}$ は血中薬物濃度 の測定值であるから， $y_{j}>0$ である．この範囲で

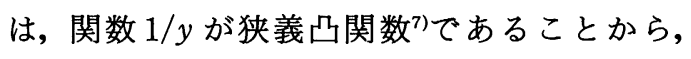
ジェンセンの不等式 (Jensen's inequality) ${ }^{8,9} に$ によ り, 条件 $E\left[y_{j}\right]=f\left(t_{j}, \boldsymbol{\theta}\right)$ のもとで

$$
E\left[\frac{1}{y_{j}}\right]>\frac{1}{E\left[y_{j}\right]}=\frac{1}{f\left(t_{j}, \boldsymbol{\theta}\right)}
$$

となる.したがって, $E\left[f\left(t_{j}, \boldsymbol{\theta}\right) / y_{j}\right]>1$ となり条 件(7)は成り立たず, 式(6)において $E[\partial U(\boldsymbol{\theta}) /$ $\partial \boldsymbol{\theta}] \neq 0$ となる.

以上より, $w_{j}=1 / y_{j}$ の重み付けを用いた場合に 
は, 条件 $E\left[y_{j}\right]=f\left(t_{j}, \boldsymbol{\theta}\right)$ が成り立っていても式 (4)の条件は成り立たないため, 式(3)の解である $\hat{\boldsymbol{\theta}}$ は一致推定量ではなくなり, バイアスが入るこ とになる。

$w_{j}=1 / y_{j}{ }^{2}$ という重み付けを用いた場合も式(6) と同様に考えると, 条件(4)が成り立つためには

$$
E\left[\frac{1}{y_{j}}\right]=E\left[\frac{f\left(t_{j}, \boldsymbol{\theta}\right)}{y_{j}{ }^{2}}\right]
$$

が成り立たなければならない. $1 / y_{j}$ の分散を $V a r$ $\left[1 / y_{j}\right]$ とすると,

$$
\begin{aligned}
E & {\left[\frac{1}{y_{j}{ }^{2}}\right] } \\
& =\left\{E\left[\frac{1}{y_{j}}\right]\right\}^{2}+\operatorname{Var}\left[\frac{1}{y_{j}}\right] \\
& \left.>\left\{E\left[\frac{1}{y_{j}}\right]\right\}^{2} \quad \text { (because } \operatorname{Var}\left[\frac{1}{y_{j}}\right]>0\right) \\
& >E\left[\frac{1}{y_{j}}\right] \frac{1}{f\left(t_{j}, \boldsymbol{\theta}\right)} \quad \text { (from (8)) }
\end{aligned}
$$

であるから, $E\left[f\left(t_{j}, \boldsymbol{\theta}\right) / y_{j}{ }^{2}\right]>E\left[1 / y_{j}\right]$ となる. したがって, 条件(9) は成り立たず, $E[\partial U(\boldsymbol{\theta}) / \partial$ $\boldsymbol{\theta}] \neq 0$ となる.

以上より, $w_{j}=1 / y_{j}{ }^{2}$ という重み付けを用いた場 合にも, やはり式(4)の条件は成り立たないため, 式(3)の解である $\hat{\boldsymbol{\theta}}$ は一致推定量ではなくなり, バイアスが入ることになる.

\section{2. 静脈内注射の1-コンパートメントモデルに おける検討}

本節では, 最も単純な薬物動態学的モデルであ る静脈内注射の1-コンパートメントモデルにつ いて，前節で指摘した問題点をシミュレーション により検討する。

このモデルでは, 式(1)の $f\left(t_{j}, \boldsymbol{\theta}\right)$ は次式で定義 される。

$$
f\left(t_{j}, \boldsymbol{\theta}\right)=\frac{D}{V} \exp \left(-K t_{j}\right)
$$

ここで, $\boldsymbol{\theta}=(K, V)^{T}$ は被験者の薬物動態学的パ ラメータベクトル， $K$ と $V$ は消失速度定数 (elimination rate constant) と分布容積 (distribution
volume)，D は投与量をそれぞれ表す.

今回のシミュレーションでは, 薬物動態学的パ ラメータと投与量をそれぞれ $V=100(L), K=$ $0.693\left(h r^{-1}\right), D=500(m g)$ とした. 消失速度定数 $K$ の值は, Sheiner and Beal ${ }^{1)}$ 参考とした。測 定時点は, 投与直後, 投与後 5 分, 10 分, 15 分, 30 分, 45 分, 1 時間, 1.5 時間, 2 時間, 3 時間, 4 時間, 6 時間, 8 時間, 10 時間, 12 時間, 24 時 間の 16 時点とした。半減期が $\ln 2.0 / K \approx$ $1.0(h r)$ であることから, 測定時点についてはこ の設定で十分と考えられる.

式(1)の誤差項 $\varepsilon_{j}$ については，一般に血中薬物 濃度が高いほどそのばらつきも大きいことから， Sheiner and Beal ${ }^{1)}$ と同様に, 誤差項の変動係数を 一定とするモデル (constant coefficient of variation model)

$$
\varepsilon_{j} \sim N\left(0,\left\{\alpha f\left(t_{j}, \boldsymbol{\theta}\right)\right\}^{2}\right), \quad j=1, \cdots, m
$$

を用いる．ここで， $\alpha$ は変動係数である．シミュ レーションにおける変動係数の值は, $0.05,0.10$, $0.15,0.20,0.25$ の 5 通りとした。

シミュレーションの回数は 10,000 回とし, 各回 ごとに得られた推定值の誤差を

$$
\frac{(\text { 推定値－真値） }}{\text { 真値 }} \times 100(\%)
$$

として評価したうえで, 10,000 回の誤差の平均と して推定値のバイアスを評価した.

結果を Table 1 に示す. 分布容積の推定値には 正のバイアス, 消失速度定数の推定值にはわずか に負のバイアスが入っており，バイアスの絶対值 は詿差項の変動係数の值とともに大きくなってい ることがわかる．とくに分布容積の推定值につい ては, 変動係数が 0.20 を越えると $10 \%$ 以上のバ イアスが入っている.

Sheiner and Beal ${ }^{1)}$ は本論文と同様に, 誤差項に 変動係数を一定とするモデル(11)を仮定した静脈 内注射の 1-コンパートメントモデルで, 変動係数 を 0.15 とした場合についてのシミュレーション による検討を行っている.彼らは式(10)において, $1 / V$ と $K$ をパラメータとして設定し, 変動係数 
Table 1 静脈内注射の1-コンパートメントモデルを用いたシミュレーショ ンにおけるパラメータの推定値のバイアスとその 95\%信頼区間*1

\begin{tabular}{cccl}
\hline \multirow{2}{*}{ 変動係数*2 } & \multicolumn{3}{c}{ 推定值のバイアス (単位 $: \%)$} \\
\cline { 2 - 4 } & \multicolumn{2}{c}{ 分布容積 } & \multicolumn{2}{c}{ 消失速度定数 } \\
\hline 0.05 & $0.471(0.441 \sim 0.501)$ & -0.00816 & $(-0.0136 \sim-0.00268)$ \\
0.10 & $2.001(1.936 \sim 2.066)$ & -0.0444 & $(-0.0560 \sim-0.0328)$ \\
0.15 & $4.756(4.645 \sim 4.867)$ & -0.0908 & $(-0.109 \sim-0.0723)$ \\
0.20 & $9.308(9.129 \sim 9.487)$ & -0.175 & $(-0.203 \sim-0.147)$ \\
0.25 & $16.703(16.383 \sim 17.024)$ & -0.210 & $(-0.254 \sim-0.165)$ \\
\hline
\end{tabular}

${ }^{* 1}$ 括弧内に $95 \%$ 信頼区間を示す.

*2 誤差項の変動係数

が 0.15 の場合に $1 / V$ の推定值に負のバイアス が入る, すなわち分布容積 $V$ の推定值に正のバ イアスが入る可能性を示唆している. 彼らの結果 は今回の我々の結果と一致するものであり興味深 い. なお, 消失速度定数の推定值のバイアスに関 しては，彼らの論文では言及されていない。

\section{結 語}

本論文の最初でも述べたように，測定值自身に よる重み付けを用いた非線形最小二乗法は, 測定 值をそのまま重みとして使えるという簡便さもあ るため, 実際の薬物動態解析にしばしば用いられ ているのが, 本論文で指摘した統計学的問題点に ついては, ほとんど知られていないのが現状であ る. そのため, バイアスの入ったパラメータの推 定值に基づく検討が行われている危険性が高い.

前節では, 最も単純な薬物動態学的モデルであ る静脈内注射の1-コンパートメントモデルにつ いての検討を行ったが, その他の, より複雑なモ デルにおいても同様の問題が生じているはずであ り, 十分な注意が必要である。また, 前節で検討 した重み付けのうち, $w_{j}=1 / y_{j}{ }^{2}$ という重み付けに ついて, Sheiner and Beal'1は彼らの論文の Discussionにおいて, “Weighted Least Squares with reciprocal squared observation weighting $\left[W L S\left(y^{-2}\right)\right]$ is clearly the worst of all methods and should be abandoned. This method appears to be the most popular weighting method in pharmacokinetics. However, we know of no studies establishing its superiority over any other method.”と明確に述べている.

本論文で指摘した問題点を回避する 1 つの方法 として, 重み $w_{j}$ を測定值自身の関数とするので はなく, 薬物動態学的モデルにより推定され た值, すなわち式(1)の $f\left(t_{j}, \boldsymbol{\theta}\right)$ の関数として $w_{j}\left(f\left(t_{j}, \boldsymbol{\theta}\right)\right)$ という形で重み付けをする方法が挙 げられる。この重み付けを用いた方法の 1 つに, 一般化最小二乗法 (generalized least squares method)があり, そのアルゴリズムの概略を以下 に示しておく.

Step 1: パラメータ $\boldsymbol{\theta}$ の初期值を $\boldsymbol{\theta}_{0}$ として与 え, 重みを $w_{j}\left(f\left(t_{j}, \boldsymbol{\theta}_{0}\right)\right)$ とする.

Step 2: 重み $w_{j}\left(f\left(t_{j}, \boldsymbol{\theta}_{0}\right)\right)$ を用いて, 重み付き 最小二乗法により, パラメータの推定 值 $\hat{\boldsymbol{\theta}}$ を得る。

Step 3 : 推定值 $\hat{\boldsymbol{\theta}}$ 用いて, 重みを $w_{j}\left(f\left(t_{j}\right.\right.$, $\hat{\boldsymbol{\theta}}))$ として更新する。

Step 4 : 更新された重み $w_{j}\left(f\left(t_{j}, \hat{\boldsymbol{\theta}}\right)\right)$ を用い て, 重み付き最小二乗法により, パラ メータの推定值 $\hat{\boldsymbol{\theta}}$ を更新する.

Step 5：上記の Step 3，4 を収束するまで繰り 返し, 最終的なパラメータの推定值を 得る.

このアルゴリズムを用いた一般化最小二乗法 では, 条件(4)が成り立つため, 一致推定量が得 られる2)(この方法の詳細については, 参考文献 2）などを参照). 
最小二乗法の中でも, population pharmacokinetics などで用いられる拡張最小二乗法 (extended least squares method）では, 測定值の一 次のモーメントだけでなく二次のモーメント，す なわち分散共分散行列についてもモデル化をした うえで，モデルに含まれるすべてのパラメータを 一度に推定している。 そのため, 最尤法 (maximum likelihood method) の場合と同様に，一次 のモーメントだけでなく二次のモーメントのモデ ル化も正しくないかぎり, 一致推定量は得られな い(この問題点の詳細については, 参考文献 10) および 11)を参照). 拡張最小二乗法を実際の解析 に用いる場合には, この点に対する十分な注意が 必要である。

\section{謝辞}

本論文に関する有益なコメントをいただいた編集 委員ならびに査読者の方々に心より感謝いたします。 本論文の一部は, 統計数理研究所共同研究プログラ ム（12-共研-1004）の援助を受けたものである.

\section{文献}

1) Sheiner, L. B. and Beal, S. L. : Pharmacokinetic parameter estimates from several least squares procedures: Superiority of extended least squares. J. Pharmacokin. Biopharm., 13:185-201 (1985).

2) Carroll, R. J. and Ruppert, D. : Transformation and Weighting in Regression, Chapman \& Hall, New York (1988).

3) Davidian, M., Giltinan, D. M. : Nonlinear Models for Repeated Measurement Data, Chapman \& Hall, London (1995).

4) Huber, P. J. : The behavior of maximum likelihood estimates under nonstandard conditions. Proc. Fifth Berkeley Symposium on Mathematical Statistics and Probability, Vol. 1, University of California Press, Berkeley, pp. 221-233 (1967).

5) Huber, P. J. : Robust Statistics, Wiley, New York (1981).

6) Shao, J. : Mathematical Statistics, Springer, New York (1999).

7) 今野 浩, 山下 浩: 非線形計画法, 日科技連, 東 京 (1978).

8) Rao, C. R. : Linear Statistical Inference and Its Applications, 2nd ed., Wiley, New York (1973).

9）竹村彰通：現代数理統計学, 創文社, 東京 (1991).

10) van Houwelingen, J.C.: Use and abuse of variance models in regression. Biometrics, $44: 1073-$ 1081 (1988).

11) Takeuchi, M. and Yafune, A.: Notes on the consistency of estimators derived from nonlinear models for clinical repeated measurements. Communications in Statistics (submitted).

\title{
FORUM
}

\section{A Statistical Issue Regarding Nonlinear Least Squares Approaches with Observation Weighting for Pharmacokinetic Analysis}

\author{
Akifumi YAFUNE* \\ * Division of Biostatistics, Kitasato University Graduate School \\ 5-9-1 Shirokane, Minato-ku, Tokyo 108-8641, Japan
}

Nonlinear least squares methods with observation weighting are often used for applying pharmacokinetic models to individual pharmacokinetic profiles. The observation weighting, however, causes biased and inconsistent estimates of pharmacokinetic parameters. This paper describes the statistical issue regarding nonlinear least squares methods with observation weighting, and presents a simulation study using a onecompartment model with bolus intravenous injection.

Key words : consistency, $M$-estimator 